\title{
Efficacy of allopurinol and benzbromarone for the control of hyperuricaemia. A pathogenic approach to the treatment of primary chronic gout
}

\author{
F Perez-Ruiz, A Alonso-Ruiz, M Calabozo, A Herrero-Beites, G García-Erauskin, \\ E Ruiz-Lucea
}

\begin{abstract}
Objectives-To study the efficacy of allopurinol and benzbromarone to reduce serum urate concentrations in patients with primary chronic gout.

Methods-Prospective, parallel, open study of 86 consecutive male patients with primary chronic gout. Forty nine patients (26 normal excretors and 23 under excretors) were given allopurinol $300 \mathrm{mg} /$ day and 37 under excretors benzbromarone $100 \mathrm{mg} /$ day. After achieving steady plasma urate concentrations with such doses, treatment was then adjusted to obtain optimal plasmatic urate concentrations (under $6 \mathrm{mg} / \mathrm{dl}$ ).

Results-Patients receiving allopurinol $300 \mathrm{mg} /$ day showed a mean reduction of plasmatic urate of $2.75 \mathrm{mg} / \mathrm{dl}$ (from 8.60 to $5.85 \mathrm{mg} / \mathrm{dl}$ ) and $3.34 \mathrm{mg} / \mathrm{dl}$ (from 9.10 to $5.76 \mathrm{mg} / \mathrm{dl}$ ) in normal excretors and under excretors respectively. Patients receiving benzbromarone $100 \mathrm{mg} /$ day achieved a reduction of plasmatic urate of $5.04 \mathrm{mg} / \mathrm{dl}$ (from 8.58 to $3.54 \mathrm{mg} / \mathrm{dl}$ ). Fifty three per cent of patients receiving allopurinol and $100 \%$ receiving benzbromarone achieved optimal plasma urate concentrations at such doses. The patients with poor results with allopurinol $300 \mathrm{mg} / \mathrm{day}$ achieved a proper plasma urate concentration with allopurinol 450 to $600 \mathrm{mg} / \mathrm{day}$, the mean final dose being 372 mg/day. Renal fuction improved and no case of renal lithiasis was observed among benzbromarone treated patients, whose mean final dose was 76 mg/day.

Conclusion-Benzbromarone is very effective to control plasma urate concentrations at doses ranging from 50 to 100 mg/day. Uricosuric treatment is a suitable approach to the treatment of patients with gout who show underexcretion of urate. (Ann Rheum Dis 1998;57:545-549)
\end{abstract}

Hospital de Cruces, Pais Vasco, Spain Rehabilitation Division, Hospital de Gorliz, Pais Vasco, Spain

A Herrero-Beites

Correspondence to: Dr F Perez-Ruiz, Sección de Reumatología, Hospital de Cruces, Pza de Cruces sn, 48903 Barakaldo, Vizcaya, Spain.

Accepted for publication 8 July 1998 ar tissue to stop the deposition of crystals and allow the dissolution of existing ones. This is clearly stated in most textbooks and reviews published during the past 50 years. ${ }^{1-7}$

The evidence of when to start urate lowering drug (ULD) treatment is conflicting: most authors support that ULD treatment should be considered after a first episode, ${ }^{3}$ some advocate that only patients who suffer more than four episodes/year should be given ULDs, ${ }^{8}$ and others that such a decision should be on an individual patient basis. ${ }^{9}$ However, most authors agree that patients with chronic gouty arthritis with or without articular or soft tissue tophi should be given ULDs. ${ }^{2-7}{ }^{9-11}$ Recently, Ferraz and O'Brien have shown that "ULD treatment is cost effective, and cost saving in patients that present 2 or more recurrent attacks per year". ${ }^{11}$ Three questions arise then for physicians and patients: which drug? (should be prescribed), how much? (should plasma urate be lowered), and how long? (should it remain low)?

Despite the fact that benzbromarone and allopurinol have been available for the treatment of gout for more than 20 years in Europe, we could not find a comparative study in the literature (MEDLINE search). This study was carried out to compare the efficacy of allopurinol and benzbromarone, in lowering plasma urate concentrations below those considered therapeutic for the dissolution of MSU crystals in tissues, ${ }^{12-16}$ using a pathogenic approach.

\section{Methods}

A prospective, parallel, open study was carried out in patients consecutively referred to a hospital rheumatology unit. The following conditions had to be met for the patients to be considered for inclusion in the study: (1) the 1977 ARA criteria for the classification of gout ${ }^{17} ;(2)$ the patient not to have received urate lowering treatment one month before entering the study; (3) absence of concomitant treatment or disease known to cause hyperuricaemia; (4) avoidance of drugs known to have uricosuric effect or interfere with the efficacy or metabolism of allopurinol or benzbromarone (such as salicylates, diuretics or amiodarone); (5) no significant liver disease or renal disease (clearance of creatinine should be over $60 \mathrm{ml} / \mathrm{min} /$ $\left.1.73 \mathrm{~m}^{2}\right)$

Before entering the study all patients had complete blood cell count, liver function, plasmatic urate (Pur), plasmatic creatinine (Pcr), clearance of creatinine (Ccr), clearance of urate (Cur), and urinary uric acid excretion (24 h Uur) on unrestricted purine diet. Ccr, Cur, and $24 \mathrm{~h}$ Uur were calculated using a 24 hour urine 
sample and normalised for a body surface area of $1.73 \mathrm{~m}^{2}$. Plasmatic and urinary uric acid determinations were performed by uricase method (Boehringer-Manheim). Prophylaxis of gouty episodes was prescribed to all patients: colchicine $1 \mathrm{mg} /$ day (or diclofenac $50 \mathrm{mg} /$ day when a previous history of adverse effects or intolerance to colchicine was present) up to three months after an optimal level of Pur was achieved.

Patients were asked to avoid alcoholic beverages and take a normocaloric, unrestricted purine diet. A hypocaloric diet (2000 kcal/day) was prescribed to patients who were overweight. Alcohol intake and being overweight have been shown to correlate to poor control of plasma urate concentrations. ${ }^{18} 19$ The Cur was considered normal when it exceeded 6 $\mathrm{ml} / \mathrm{min} / 1.73 \mathrm{~m}^{2021}$ and patients were classified as normoexcretors (overproducers) when they showed Cur $6 \mathrm{ml} / \mathrm{min} / 1.73 \mathrm{~m}^{2}$, and as underexcretors when Cur $<6 \mathrm{ml} / \mathrm{min} / 1.73 \mathrm{~m}^{2}$. Patients showing overproduction were given allopurinol $300 \mathrm{mg}$ orally once a day. Also patients with underexcretion of urate were treated with allopurinol $300 \mathrm{mg} /$ day who showed: (1) prominent soft tissue tophi; (2) a history of possible nephrolithiasis; (3) 24 h Uur over 700 $\mathrm{mg} /$ day despite Cur $<6 \mathrm{ml} / \mathrm{min}$. The rest of the patients with underexcretion of urate were given benzbromarone $100 \mathrm{mg}$ orally once a day. Patients treated with benzbromarone were encouraged to obtain diuresis of over $1 \mathrm{ml} / \mathrm{min}$ throughout the study (urine output was checked in each control visit), but no alkali was initially prescribed.

Measurements of Pur, Pcr, Cur, Ccr, $24 \mathrm{~h}$ Uur in 24 hour urine samples, and liver tests were performed every three months. Complete blood cell counts were made at least twice a year. The presence of uric acid crystals was investigated in urine samples from patients treated with benzbromarone. Urate lowering treatment was considered steady when Pur did not differ by more than $1 \mathrm{mg} / \mathrm{dl}$ in two consecutive measurements. Once a steady Pur level was achieved, a first analysis of data was performed. Allopurinol and benzbromarone doses were adjusted to achieve optimal Pur concentrations - that is, under $6.0 \mathrm{mg} / \mathrm{dl},(357$ $\mu \mathrm{mol} / \mathrm{l})^{6{ }^{14-16}}$ in all patients and to avoid $24 \mathrm{~h}$ Uur concentrations higher than $1000 \mathrm{mg}$ /day
$(5.95 \mathrm{mmol} / \mathrm{l})$ in the patients treated with benzbromarone to minimise the risk of urolithiasis.

Statistic analysis was made with a statistic microcomputer program EPI INFO 6.0. ${ }^{20}$ Results were studied with one way analysis of variance, $t$ test, paired $t$ test, and nonparametric tests (Wilcoxon and MannWhitney) when necessary. Results from parametric tests are expressed as mean (SD).

\section{Results}

Ninety one patients entered the study. Five were excluded during follow up because of poor compliance with treatment (two patients), loss of follow up (two patients) or persistent alcohol intake (one patient). Eighty six men were available for the analysis of results. All of them fulfilled ARA criteria for the classification of gout ${ }^{17}$ and 64 of $86(74.4 \%)$ showed MSU crystals in synovial fluid samples or in material aspirated from tophi. Tophi were observed in 33 of 86 patients $(38.4 \%)$. Mean age was 52.5 (9.6) years (range 32 to 76 ) and time from onset of the symptoms of gout was 8.3 (6.7) years (range 1-30). Twenty three patients $(26.7 \%)$ were classified as normoexcretors and $63(73.3 \%)$ as underexcretors. Twenty six underexcretors were given allopurinol (12 had prominent tophi, eight had a possible or proved history of renal colic, and six showed $24 \mathrm{~h}$ Uur from 700 to $800 \mathrm{mg} /$ day). The 37 remaining underexcretors were given benzbromarone 100 $\mathrm{mg} /$ day. Table 1 shows general data, renal function tests, and renal uric acid results before treatment. Steady plasmatic urate concentrations were achieved between the sixth and the ninth month measurements in all patients.

After treatment with initial doses (fig 1), patients taking allopurinol $300 \mathrm{mg} /$ day, overproducers and underexcretors, showed a reduction of mean Pur from $8.60 \mathrm{mg} / \mathrm{dl}(512$ $\mu \mathrm{mol} / \mathrm{l})$ to $5.85 \mathrm{mg} / \mathrm{dl}(348 \mu \mathrm{mol} / \mathrm{l})$ and from $9.10 \mathrm{mg} / \mathrm{dl}(541 \mu \mathrm{mol} / \mathrm{l})$ to $5.76 \mathrm{mg} / \mathrm{dl}(344$ $\mu \mathrm{mol} / 1)$ respectively. The percentage of reduction from initial Pur was $31.69 \%$ for overproducers and $36.26 \%$ for underexcretors. There was no difference in the efficacy of allopurinol whether it was used in normoexcretors or underexcretors. Cur remained unchanged and $24 \mathrm{~h}$ Uur decreased in both groups, but was much lower in patients with underexcretion (fig 1).

Table 1 Data for before and after treatment

\begin{tabular}{lcccl}
\hline & $\begin{array}{l}\text { Overproducers } \\
\text { Allopurinol }(n=23) \\
\text { (Group 1) }\end{array}$ & $\begin{array}{l}\text { Underexcretors } \\
\text { Allopurinol }(n=26) \\
\text { (Group 2) }\end{array}$ & $\begin{array}{l}\text { Underexcretors } \\
\text { Benzbromarone (n=36) } \\
\text { (Group 3) }\end{array}$ & $\begin{array}{l}p \text { Value (for intergroup } \\
\text { comparisons) }\end{array}$ \\
\hline Age (y) & $51.4(8.2)$ & $53.8(6.4)$ & $53.1(19.8)$ & $\mathrm{NS}$ \\
Onset (y) & $9.7(6.3)$ & $7.9(5.7)$ & $8.3(7.5)$ & $\mathrm{NS}$ \\
Tophi (\%) & 43.4 & 46.1 & 31.4 & $\mathrm{NS}$ \\
iPur (mg/dl) & $8.60(0.92)$ & $9.10(1.36)$ & $8.58(1.36)$ & $\mathrm{NS}$ \\
fPur (mg/dl) & $5.85(0.87)^{\star \star \star}$ & $5.76(1.33)^{\star \star \star}$ & $3.54(1.21)^{\star \star \star \star}$ & 1 and $2 v 3<0.001$ \\
Red Pur (\%) & $31.69(9.31)$ & $36.26(13.08)$ & $58.27(14.48)$ & 1 and $2 v 3<0.001$ \\
iCcr (ml/min) & $116(22)$ & $108(21)$ & $87(22)$ & 1 and $2 v 3<0.05$ \\
fCcr (ml/min) & $119(23)$ & $110(22)$ & $104(22)^{\star \star}$ & $\mathrm{NS}$ \\
iCur (ml/min) & $6.71(0.70)$ & $4.52(1.05)$ & $3.89(1.15)$ & $2 v 3 \mathrm{NS}$ \\
fCur (ml/min) & $6.60(1.30)$ & $4.98(1.56)$ & $18.43(9.31)^{\star \star \star}$ & $2 v 3<0.001$ \\
i24 h Uur (mg) & $831(113)$ & $584(132)$ & $474(132)$ & $1 v 2$ and $3<0.01$ \\
f24 h Uur (mg) & $559(145)^{\star \star}$ & $404(125)^{\star \star}$ & $819(190)^{\star \star \star}$ & 1 and $2 v 3<0.001$ \\
\hline
\end{tabular}

iPur = initial plasmatic urate; fPur = final plasmatic urate; red Pur $(\%)=$ percentage of reduction from initial plasmatic urate (red Pur $=($ iPur $-\mathrm{fPur}) / \mathrm{iPur} \times 100) . \mathrm{iCcr}=$ initial clearance of creatinin $; \mathrm{fCcr}=$ final clearance of creatinin $;$ iCur $=$ initial clearance of urate; $\mathrm{fCur}=$ final clearance of urate; i24 h Uur $=$ initial $24 \mathrm{~h}$ urinary excretion of urate; $\mathrm{f} 24 \mathrm{~h}$ Uur $=$ final $24 \mathrm{~h}$ urinary excretion of urate. ${ }^{\star \star}$ Final $v$ initial values $\mathrm{p}<0.01 .{ }^{\star} \star \star$ Final $v$ initial values $\mathrm{p}<0.001$. Data shown as mean (SD). 
Patients taking benzbromarone $100 \mathrm{mg} /$ day showed a decrease of mean Pur from 8.58 $\mathrm{mg} / \mathrm{dl}(510 \mu \mathrm{mol} / \mathrm{l})$ to $3.54 \mathrm{mg} / \mathrm{dl}(211 \mu \mathrm{mol} / \mathrm{l})$. The percentage of reduction from initial Pur was $58.27 \%$. Mean $24 \mathrm{~h}$ Uur after treatment was $819 \mathrm{mg} /$ day (4.87 mmol/day), ranging from 586 to $1106 \mathrm{mg} /$ day ( 3.48 to $6.58 \mathrm{mmol} /$ day). There was no difference in $24 \mathrm{~h}$ Uur in patients with or without tophi: 814 (178) $\mathrm{mg} /$ day $v 821$ (199) (4.84 (1.06) and 4.88 (1.18) $\mathrm{mmol} /$ day respectively ). Cur increased from $3.89 \mathrm{ml} / \mathrm{min}$ to $18.43 \mathrm{ml} / \mathrm{min}$. There was a significant difference $(p=0.039)$ in the efficacy of benzbromarone in patients with lower initial Ccr (nine patients with Ccr from 60 to $70 \mathrm{ml} / \mathrm{min}$ ) compared with those patients with higher initial Ccr (28 patients): they showed a mean reduction of Pur of 4.12 (1.66) $\mathrm{mg} / \mathrm{dl}(245(98) \mu \mathrm{mol} / \mathrm{l})$ and $5.35(1.69) \mathrm{mg} / \mathrm{dl}$ (318 (100) $\mu \mathrm{mol} / \mathrm{l})$, respectively. No patient showed uric acid crystals on urine samples and no case of kidney stones was observed.

The mean reduction of Pur was greater in patients taking benzbromarone than that achieved in the 49 patients with allopurinol: from 8.58 to $3.54 \mathrm{mg} / \mathrm{dl}$ (5.04 mg/dl, 299 (93) $\mu \mathrm{mol} / \mathrm{l})$ and from 8.86 to $5.80 \mathrm{mg} / \mathrm{dl}(3.06 \mathrm{mg} /$ $\mathrm{dl}, 182(71) \mu \mathrm{mol} / \mathrm{l})(\mathrm{p}<0.001)$, respectively. The percentage of reduction of Pur was also different: $58.27 \%$ v $34.53 \%(\mathrm{p}<0.001)$, respectively.

None of the 37 patients taking benzbromarone $100 \mathrm{mg} /$ day failed to achieve Pur concentrations below $6 \mathrm{mg} / \mathrm{dl}$ while 23 of $49(47 \%)$ patients taking allopurinol $300 \mathrm{mg} /$ day showed Pur concentrations over $6 \mathrm{mg} / \mathrm{dl}(\mathrm{p}<0.0001)$. Sixteen of these 23 patients $(32 \%)$ ranged from 6 to $7 \mathrm{mg} / \mathrm{dl}$ and seven of them (15\%) showed Pur concentrations over $7.0 \mathrm{mg} / \mathrm{dl}$. Patients with final Pur concentrations above $6 \mathrm{mg} / \mathrm{dl}$
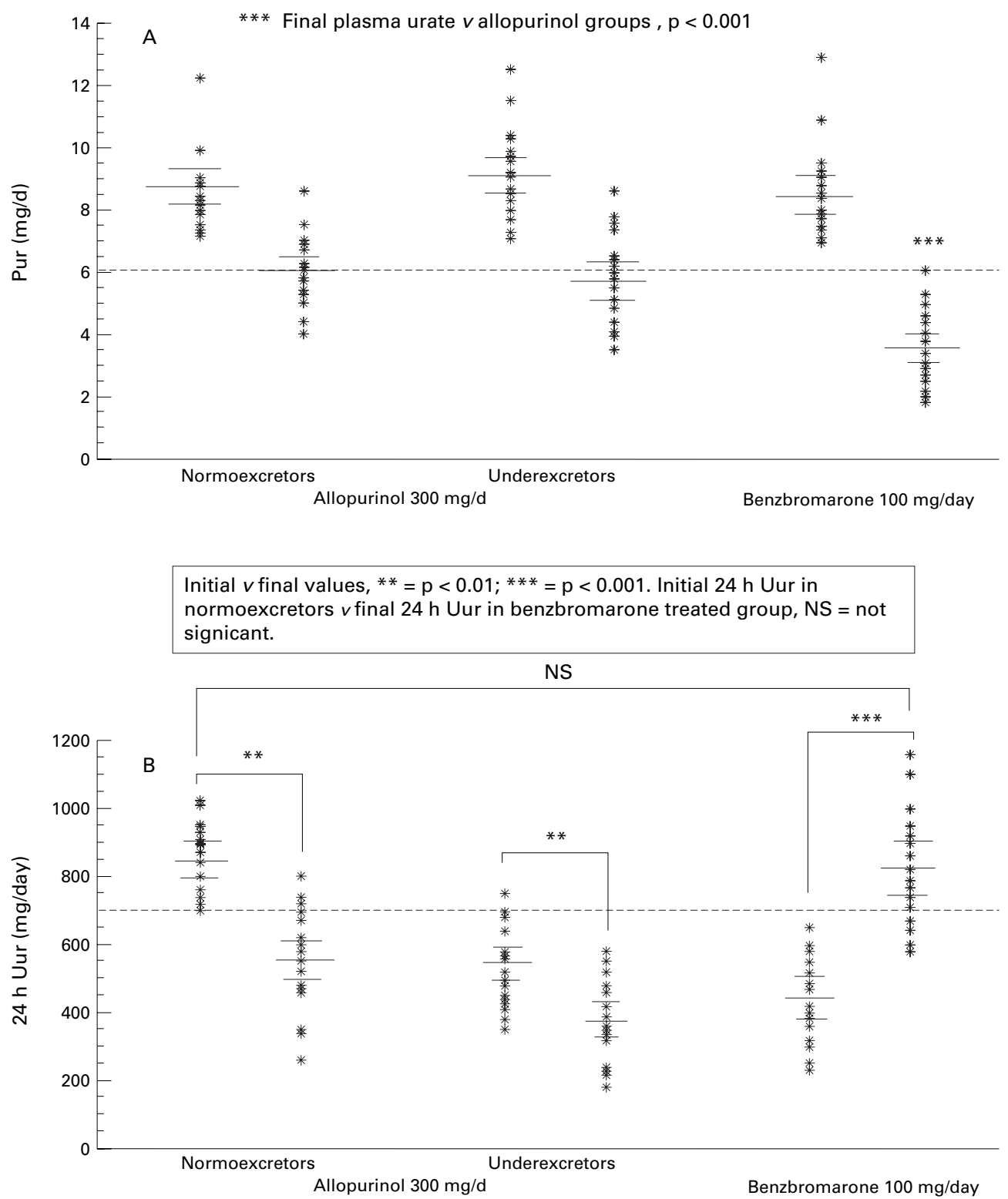

Figure 1 Initial and final plasma urate (Pur) (fig 1A) and 24 hour urinary urate (24 h Uur) (fig 1B) after standard doses of urate lowering drugs (allopurinol $300 \mathrm{mg} /$ day or benzbromarone $100 \mathrm{mg} /$ day). Note that the mean initial $24 \mathrm{~h}$ Uur in normoexcretors is not different to the mean final $24 \mathrm{~h}$ Uur from underexcretors treated with benzbromarone. Bars indicate the mean and the $95 \%$ confidence limits. 
showed an initial mean Pur value of $9.15 \mathrm{mg} / \mathrm{dl}$ $(544 \mu \mathrm{mol} / \mathrm{l})$ while patients with final Pur concentrations below $6 \mathrm{mg} / \mathrm{dl}$ showed an initial mean Pur value of $8.46 \mathrm{mg} / \mathrm{dl}(503 \mu \mathrm{mol} / \mathrm{l})$ $(p=0.019)$.

After the initial trial with standard doses of ULDs, doses were adjusted to maintain Pur under $6.0 \mathrm{mg} / \mathrm{dl}$. The dose of allopurinol had to be increased up to $450 \mathrm{mg} /$ day in 21 patients, up to $600 \mathrm{mg} /$ day in two patients and it could be reduced to $200 \mathrm{mg} /$ day in two patients. Therefore, the mean dose to obtain Pur concentrations under $6.0 \mathrm{mg} / \mathrm{dl}$ was 372 $\mathrm{mg} /$ day. Benzbromarone could be reduced to $50 \mathrm{mg} /$ day in 18 of 37 , the mean final dose being $76 \mathrm{mg} /$ day. The overall mean follow up was 12.5 (2.6) months (12.4 (2.9) for normoexcretors, 12.0 (2.8) for underexcretors taking allopurinol, and 12.1 (2.1) for underexcretors taking benzbromarone.

The mean Ccr increased in all groups after treatment, but differences were only significant in those patients treated with benzbromarone (from 87 (22) $\mathrm{ml} / \mathrm{min}$ to 104 (22) $\mathrm{ml} / \mathrm{min}, \mathrm{p}<$ $0.001)$. There was not a single case of withdrawal because of adverse reactions either to allopurinol or to benzbromarone. Two patients taking allopurinol showed a slight increase in serum alanine aminotransferase (less than twice the normal limits) and one patient taking benzbromarone suffered diarrhoea with concommitant administration of colchicine that subsided after colchicine discontinuation.

\section{Discussion}

This study shows that benzbromarone is very useful for the control of hyperuricaemia using doses ranging from 50 to $100 \mathrm{mg} /$ day. It also shows that $47 \%$ of our patients taking allopurinol did not achieve optimal Pur concentrations with $300 \mathrm{mg} /$ day despite alcohol abstinence and weight reduction. Previous studies showed that poor control of uricaemia is common, ${ }^{23-27}$ and it may result in radiological progression of bony lesions, ${ }^{23}$ increased size of tophi, ${ }^{23}$ and frequent recurrence of gouty bouts and tophi after withdrawal of urate lowering treatment. ${ }^{24} 2527$

Although most standard sources of information recommend uricosurics to correct hyperuricaemia in underexcretors, ${ }^{5-8} 2930$ this approach is not a common practice in more recent studies. ${ }^{23-26}$ Epidemiological studies show that only $2-15 \%$ of patients with gout were taking uricosuric drugs. ${ }^{30-32}$ It may be because uricosurics such as probenecid or sulphinpyrazone have to be given in a twice daily regimen and have little efficacy in patients with low Ccr, and that patients taking uricosurics should be monitored to avoid the risk of renal stones. Although benzbromarone showed a little lower efficacy in patients with the lowest Ccr, an important reduction of Pur (of 4.12 $\mathrm{mg} / \mathrm{dl}$ ) was observed in these patients.

Relative underexcretion of urate has been reported in 80 to $90 \%$ of the patients with primary gout ${ }^{29} 3334$ so uricosuric treatment would seem to be a more pathogenic approach to the treatement of hyperuricaemia for most of the patients with gout, as suggested by Wolfe et al. ${ }^{30}$ We use Cur together with $24 \mathrm{~h}$ Uur to classify patients for uricosuric treatment because Cur reflects renal handling of urate. ${ }^{35}$ Uricosurics were the first ULDs used: cincophen and salycilates were used more than 50 years ago ${ }^{1}$ and proved to be useful, but toxicity was a serious concern. ${ }^{136}$ Benzbromarone is a benzofuran that produces a uricosuric effect by inhibiting postsecretory tubular resorption of urate. ${ }^{37} \mathrm{~A}$ few reports of trials using single therapy with benzbromarone are available from the literature in the past 20 years. $^{38}{ }^{40}$ In two series (using doses that ranged from 50 to 150 $\mathrm{mg} /$ day), the average reduction of Pur concentration ranged from $54 \%$ to $63 \%$ and the mean Pur was under $5 \mathrm{mg} / \mathrm{dl} .^{38}{ }^{39}$ Benzbromarone has also been shown to be useful and well tolerated in renal transplant recipients with gout secondary to cyclosporin-A treatment with the patients showing low renal function (near to 40 $\mathrm{ml} / \mathrm{min}$ ) and the interaction between azathioprine and allopurinol in patients with a renal transplant being avoided. ${ }^{40}$

Our approach to avoid renal complications of uricosuric treatment is the following: (1) to select patients with low Cur and $24 \mathrm{~h}$ Uur, (2) to indicate allopurinol as the first drug to be used in patients with a history of kidney lithiasis or prominent tophi, and (3) to monitor urinary uric acid concentration and $\mathrm{pH}$ during treatment, the most important factors involved in uric acid lithogenesis, ${ }^{41}$ and modify them (with higher fluid intake and/or urine alkalinisation) to avoid risk of lithiasis.

Allopurinol is actually the most commonly ULD prescribed..$^{30-32}$ Although the modal value of the dose of allopurinol is $300 \mathrm{mg} /$ day (range 100 to $900 \mathrm{mg} / \mathrm{day}$ ), ${ }^{32} 47 \%$ of our patients taking allopurinol, as in other studies, ${ }^{42}$ did not achieve optimal Pur concentrations with 300 $\mathrm{mg} /$ day. By contrast, the mean dose selected by the WHO is $400 \mathrm{mg} /$ day $^{43}$ closer to the 372 $\mathrm{mg} /$ day mean dose that our patients needed to obtain Pur values under $6 \mathrm{mg} / \mathrm{dl}$.

Clearance of creatinine increased in all groups after treatment, and significantly in patients taking benzbromarone. This increase is thought to be related to the avoidance of NSAIDs after successful control of hyperuricaemia and gouty bouts in all patients and because patients with the lower renal function (on benzbromarone) were probably more prone to achieve amelioration of renal function than patients in the other groups, whose renal function was higher initially.

Both allopurinol and benzbromarone have a good safety profile, but only when prescribed to patients with symptomatic hyperuricaemia. ${ }^{44}$ The dose should be adjusted to obtain Pur $<6$ $\mathrm{mg} / \mathrm{dl}(357 \mu \mathrm{mol} / \mathrm{l})$ if possible. ${ }^{14}{ }^{15}$ Also, patients taking allopurinol with renal insufficiency or concommitant diuretic treatment have a higher risk of developing severe toxicity, ${ }^{45}$ and additional caution should be taken in patients taking concommitant azathioprine treatment. ${ }^{46}$ Benzbromarone is also a safe drug. ${ }^{39}$ As it is conjugated in the liver and excreted to the bile, caution should be taken in patients with hepatobiliary diseases although a recent report suggests that benzbromarone does not seem to cause short-term changes in 
liver function in patients with liver cirrhosis with mild to moderate liver failure (Child's stages $\mathrm{A}$ and $\mathrm{B}){ }^{47}$

Recurrent, but self limited, hepatic toxicity has been reported in a 68 year old woman taking benzbromarone. ${ }^{48}$ Subfulminant hepatitis has been reported in four patients taking high doses (300 mg/day) of benzarone-an analogue of benzbromarone-to treat peripheral vascular insufficiency. ${ }^{49} 50$ Three of four patients were over 65 years and two were taking thyroid hormones. Liver toxicity appeared after six weeks to four months from the onset of benzarone treatment. Three fatalities occurred. On the other hand, Mastbernard et $a l^{39}$ did not find any significant liver toxicity in 29 patients who were treated with benzbromarone for more than five years and up to 10 years. Monitoring of liver function tests during follow up should be recommended, especially if high doses of benzbromarone are prescribed or other benzofurans (such as amiodarone) are concommitantly used.

In conclusion, benzbromarone is very effective for the control of hyperuricaemia in patients with chronic gout. The mean dose of allopurinol needed to obtain optimal control of uricaemia was closer to that recommended by WHO than to that recommended in current literature. Uricosuric drugs (such as benzbromarone $50-100 \mathrm{mg} /$ day) should be considered for patients with underexcretion of urate, except for patients with previous nephrolithiasis as uricosuric treatment is a more physiological approach to the treatment of gout in these patients.

The authors thank Dr Eliseo Pascual, from Alicante University, for reviewing the manuscript and for his interesting suggestions. This work has not been supported by any grant either from the pharmaceutical industry, private or public institutions.

1 Cohen H. Gout. In: Copeman WSC, ed. Textbook of the rheumatic diseases. 1st ed. Edinburgh: $\mathrm{E}$ and S Livingstone, 1948:249-305.

2 Yu TF. Milestones in the treatment of gout. Am J Med 1974;56:676-85.

3 Palella TD, Kelley WN. An approach to hyperuricemia and gout. Geriatrics 1984;39:89-102

4 Wortmann RL. Management of hyperuricemia. In: McCarthy DJ, ed. Arthritis and allied conditions. 11th ed Philadelphia: Lee and Febiger, 1989:1677-90.

5 Wallace SL, Singer JZ. Therapy in gout. Rheum Dis Clin North Am 1988;14:441-57.

6 Diamond HS. Control of crystal-induced arthropathies. Rheum Dis Clin North Am 1989;15:557-67.

7 Fam AG. Strategies and controversies in the treatment of gout and hyperuricemia. Baillieres Clin Rheumatol 1990;4: 177-83.

8 Fam AG. Should patients with interval gout be treated with urate lowering drugs? J Rheumatol 1995;22:1621-3.

9 Simkin PA. Management of gout. Ann Intern Med 1979;90:812-16.

10 Ferraz MB. An evidence based appraisal of the management of nontophaceous interval gout. J Rheumatol 1995;22: of nontop $1618-20$.

11 Ferraz MB, O'Brien B. A cost effective analysis of urate lowering drugs in nontophaceous recurrent gouty arthritis. J Rheumatol 1995;22:908-14

12 Rosenthal AK, Ryan LM. Treatment of refractory crystalassociated arthritis. Rheum Dis Clin North Am 1995;21: 151-61.

13 Fiddis RW, Vlachos N, Calvert PD. Studies on crystallisation in relation to gout. Ann Rheum Dis 1983;42 (suppl) $12-15$.

14 Gast LF. Reduce serum uric acid levels before withdrawing antihyperuricemic therapy in patients with tophaceous gout. [Letter]. Arthritis Rheum 1992;35:1252

15 Mc Carthy GM, Wortmann RL. [Reply to the letter to the editor]. Arthritis Rheum 1992;35:1252.

16 Emmerson BT. The management of gout. N Engl J Med 1996;334:445-51.

17 Wallace SL, Robinson H, Masi AT, Decker JL, McCarty DJ, YU TF. Preliminary criteria for the classification of the YU TF. Preliminary criteria for the classification of the
acute arthritis of primary gout. Arthritis Rheum 1977;20: acute arth
18 Ralston SH, Capell HA, Sturrock RD. Alcoholic response to treatment of gout. BMJ 1988;296:1641-2.

19 Nichols A, Scott JT. Effect of weight-loss on plasma and urinary levels of uric acid. Lancet 1972;ii:1223-4.

20 Garcia J, Mateos F, Jimenez M, Ramos T. Renal excretion of hypoxanthine and xanthine in primary gout. Am J Med 1988;85:533-7.

21 Kaehny WD, Tangel DJ, Johnson AM, Kimberling WJ, Schrier RW, Gabow PA. Uric acid handling in autosomal dominant polycystic kidney disease with normal filtration rates. Am J Med 1990;89:49-52.

22 Dean AG, Dean JA, Coulumbier D, Burton KA, Brendel $\mathrm{KA}$, Smith DC, et al. Epi Info, version 6: a word processing, database, and statistics program for epidemiology on microcomPrevention, 1994.

23 McCarthy GM, Barthelemy CR, Veum JA, Wortmann RL. Influence of antihyperuricemic therapy on the clinical and radiographic progression of gout. Arthritis Rheum 1991; 34:1489-94.

24 Bull PW, Scott JT. Intermittent control of hyperuricemia in the treatment of gout. J Rheumatol 1989;16:1246-8.

25 Loebl WY, Scott JT. Withdrawal of allopurinol in patients with gout. Ann Rheum Dis 1974;33:304-7.

26 Nakayama DA, Barthelemy C, Carrera G, Lightfoot RW Jr, Wortmann RL. Tophaceous gout: a clinical and radiographic assessment. Arthritis Rheum 1984;27:468-71

27 Lieshout-Zuidema MF, Breedveld F. Withdrawal of longterm antihyperuricemic therapy in tophaceous gout. J Rheumatol 1993;20:1383-5.

28 Gast LF. Withdrawal of longterm antihyperuricemic therapy in tophaceous gout. Clin Rheumatol 1987;1:70-3.

9 Boss GR, Seegmiller JE. Hyperuricemia and gout. N Engl J Med 1979;300:1459-68.

30 Wolf F, Cathey MA. The misdiagnosis of gout and hyperuricemia. J Rheumatol 1991;18:1232-4.

31 Bellamy N, Gilbert JR, Brooks PM, Emmerson BT, Campbell J. A survey of current prescribing practices of antiinflammatory and urate lowering drugs in gouty arthritis in the province of Ontario. J Rheumatol 1988;15: 1841-7

32 Harris CM, Lloyd DCEF, Lewis J. The prevalence and prophylaxis of gout in England. J Clin Epidemiol 1995;48: 1153-8.

33 Levinson DJ. Clinical gout and the pathogenesis of hyperu11th ed. Philadelphia: Lee and Febiger, 1989:1645-76.

34 Cohen MG, Emmerson BT. Crystal arthropathies: gout. In: Kippel JH, Dieppe PA, eds. Rheumatology. 1st ed. London: Mosby-Years Book Europe, 1994:7/12.1-7/12.16.

35 Perez-Ruiz F, Calabozo M, Alonso-Ruiz A, Ruiz-Lucea E, Herrero-Beites A. Analysis of the methods for the classification of renal handling of urate in gout. Arthritis Rheum 1997;40 (suppl):S48.

36 Cutrin C, Nieto E, Batalla A, Casal L, Perez E, Lorenzo V. Toxic hepatitis due to cincophen. Report of three cases. [English abstract]. Med Clin (Barc) 1991;97:104-6.

37 Sinclair DS, Fox IH. The pharmacology of hypouricemic effect of benzbromarone. J Rheumatol 1974;2:437-45.

38 Sorensen LB, Levinson DJ. Clinical evaluation of benzbromarone. A new uricosuric drug. Arthritis Rheum 1976;19: 183-90.

39 Masbernard A, Giudicelli CP. Ten years' experience with benzbromarone in the management of gout. South Afr Med J 1981;59:701-6.

40 Zürcher RM, Bock HA, Thiel G. Excellent uricosuric efficacy of benzbromarone in cyclosporin-A-treated renal transplant patients patients: a prospective study. Nephrol transplant patients patients: a pros
Dial Transplant 1994;9:548-51.

41 Asplin JR. Uric acid stones. Semin Nephrol 1996;5:412-24.

42 Bautler AM, Rull M, Schlechinger N, Baker DG, Hoffman BI, Schumacher HR Jr. Allopurinol may have protective effect against acute gouty arthritis independent from its hypouricemic action. Arthritis Rheum 1996;39 suppl:S86.

43 WHO collaboratory center for drug statistics methodology. Anatomical therapeutic chemical (ATC) classification index. Including defined daily dosis (DDDs) for plain substances. Oslo: WHO, 1993.

44 Singer TZ, Wallace S. The allopurinol hypersensitivity syndrome. Unnecessary morbidity and mortality. Arthritis Rheum 1986;29:82-7

45 Hande KR, Noone RM, Stone WJ. Severe allopurinol toxicity: Description and guidelines for prescription in patients with renal insufficiency. Am J Med 1984;76:4756.

46 Cummings D, Sekar M, Halil O, Banner N. Myelosuppression associated with azathioprine-allopurinol interaction after heart and lung transplantation. Transplantation 1996; $61: 1661-2$.

47 Walter-Sack I, de Vries JX, von Bubnoff A, Pfleilschifler V, Reedsch R. Biotransformation and uric acid lowering effect of benzbromarone in patients with liver cirrhosis - evidence for active benzbromarone metabolites? Eur J Med Res 1995; $1: 16-20$

48 Van der Klauw MM, Houtman PM, Stricker BH, Spoelstee P. Hepatic injury caused by benzbromarone. J Hepatol 1994;20:376-9.

49 Gehenot M, Horsmans Y, Rahier J, Geubel AP. Subfulminant hepatitis requiring liver transplantation after benzarone administration. J Hepatol 1994;20:842-6.

50 Hautekeete ML, Henrion J, Naegels S, De Neve A, Adler M, Deprez C, et al. Severe hepatotoxicity related to benzarone: report of three cases with two fatalities. Liver $1995 ; 15: 25-9$. 